\title{
Lack of Hypoxia-Inducible Factor-1 $\alpha$ Impairs Midbrain Neural Precursor Cells Involving Vascular Endothelial Growth Factor Signaling
}

\author{
Javorina Milosevic, ${ }^{1}$ Martina Maisel, ${ }^{2}$ Florian Wegner, ${ }^{1}$ Julia Leuchtenberger, ${ }^{1}$ Roland H. Wenger, ${ }^{3}$ Manfred Gerlach, ${ }^{4}$ \\ Alexander Storch, ${ }^{2}$ and Johannes Schwarz ${ }^{1}$ \\ ${ }^{1}$ Department of Neurology, University of Leipzig, 04103 Leipzig, Germany, ${ }^{2}$ Department of Neurology, Technical University of Dresden, 01307 Dresden, \\ Germany, ${ }^{3}$ Institute of Physiology, University of Zürich, 8057 Zürich, Switzerland, and ${ }^{4}$ Clinical Neurochemistry, Department of Child and Youth Psychiatry \\ and Psychotherapy, University of Würzburg, 97080 Würzburg, Germany
}

Oxygen tension is critical for proliferation of human and murine midbrain-derived neural precursor cells (mNPCs). Here, we conditionally inactivated the hypoxia-responsive transcription factor hypoxia-inducible factor-1 $\alpha(\mathrm{HIF}-1 \alpha)$ in murine NPCs to determine its role in proliferation, survival, and dopaminergic differentiation in vitro as well as survival of murine dopaminergic neurons in vivo. HIF- $1 \alpha$ conditional knock-out (HIF-1 $\alpha$ CKO) mNPCs showed midbrain-specific impairment of survival and proliferation. Dopaminergic differentiation of HIF- $1 \alpha$ CKO mNPCs in vitro was markedly reduced. Expression of vascular endothelial growth factor (VEGF) mRNA was reduced in HIF- $1 \alpha$ CKO mNPCs, whereas erythropoietin signaling was not affected. Treatment of HIF- $1 \alpha$ CKO mNPCs with $50 \mathrm{ng} / \mathrm{ml}$ VEGF partially recovered proliferation and dopaminergic differentiation in vitro. In substantia nigra (SN) of adult HIF- $1 \alpha$ CKO mice, protein levels of dopaminergic marker molecules such as tyrosine hydroxylase $(\mathrm{TH})$ and aldehyde dehydrogenase were reduced by 41 and $61 \%$, respectively. The cell survival marker Bcl-2 was reduced by $58 \%$ while caspase-3 was activated. Nonbiased stereological cell counts of TH-positive neurons in SN of young adult HIF- $1 \alpha$ CKO mice revealed a reduction of $31 \%$ compared with cre/wt mice (in which the wildtype Hifla allele is expressed in parallel with the Cre recombinase allele). However, we found no impairment of striatal dopamine concentrations or locomotor behavior. In conclusion, HIF- $1 \alpha$ seems to be a transcription factor relevant to the development and survival of substantia nigra dopaminergic neurons involving VEGF signaling.

Key words: neural precursor cells; hypoxia; HIF-1 $\alpha$; midbrain; dopaminergic development; apoptosis; VEGF

\section{Introduction}

Neural precursor cells (NPCs) offer a great promise for developing new medical treatments for disorders such as Parkinson's disease (PD) (Gage, 2003; Alvarez-Buylla and Lim, 2004). It is necessary to understand the mechanisms governing cell proliferation, dopaminergic differentiation, and senescence of NPCs to facilitate clinical therapies (Sharpless and DePinho, 2004). Reduced oxygen tension is now recognized as a common requirement for successful expansion and dopaminergic differentiation of NPCs (Ivanovic et al., 2000; Morrison et al., 2000; Studer et al., 2000; Storch et al., 2001; Milosevic et al., 2005). Low, physiologic oxygen conditions help maintain the undifferentiated state in

\footnotetext{
Received June 13, 2006; revised Dec. 4, 2006; accepted Dec. 5, 2006.

This work was supported in part by Interdisziplinäres Zentrum für Klinische Forschung Leipzig Grant TP C27 and the Research Program of the Medical Faculty Carl Gustav Carus of the Technical University of Dresden. We thank Ute Roemuss, Annett Brandt, Sylvia Kanzler, Rainer Burger, and Sabine Gehre for stem cell preparation and/or excellent technical assistance. We thank Dr. Randall S. Johnson for providing HIF- $1 \alpha$-floxed mice.

Correspondence should be addressed to Dr. Javorina Milosevic, Department of Neurology, Max-BürgerForschungszentrum, Johannisallee 30,04103 Leipzig, Germany. E-mail: javorina.milosevic@ medizin.uni-leipzig.de.

DOI:10.1523/JNEUROSCI.2482-06.2007

Copyright $\odot 2007$ Society for Neuroscience $\quad$ 0270-6474/07/270412-10\$15.00/0
}

mouse NPCs, but the molecular mechanisms underlying oxygen effects on NPCs are essentially unknown (Milosevic et al., 2005).

Many $\mathrm{O}_{2}$-responsive genes are regulated via hypoxiainducible factor-1 (HIF-1), a heterodimer consisting of HIF- $1 \alpha$ and HIF-1 $\beta$ (also called aryl hydrocarbon receptor nuclear translocatorm, or ARNT) (Semenza, 1999; Wenger, 2002). HIF-1 $\alpha$ abundance is regulated by proteasomal degradation, and its activity is regulated by diverse posttranslational modifications. HIF- $1 \alpha$ target genes include vascular endothelial growth factor (VEGF), a potent inducer of angiogenesis, and erythropoietin (EPO). Both have pleiotropic effects in the brain, including neurogenesis and neuroprotection (Sakanaka et al., 1998; Junk et al., 2002; Ferriero, 2005; Greenberg and Jin, 2005), as well as substantial regenerative effects on dopaminergic neurons (Studer et al., 2000; Yasuhara et al., 2005).

HIF- $1 \alpha$ is essential for the early development of many mammalian organs including brain (Ryan et al., 1998; Tomita et al., 2003). Mice lacking HIF- $1 \alpha$ show severe cardiac and vascular malformations, leading to embryonic lethality at approximately embryonic day 10.5 (E10.5) (Iyer et al., 1998). To study the impact of HIF- $1 \alpha$ on NPCs and, in particular, dopaminergic differentiation of midbrain-specific NPCs (mNPCs), we conditionally knocked out HIF- $1 \alpha$ exon 2 in NPCs using Nestin promoter- 


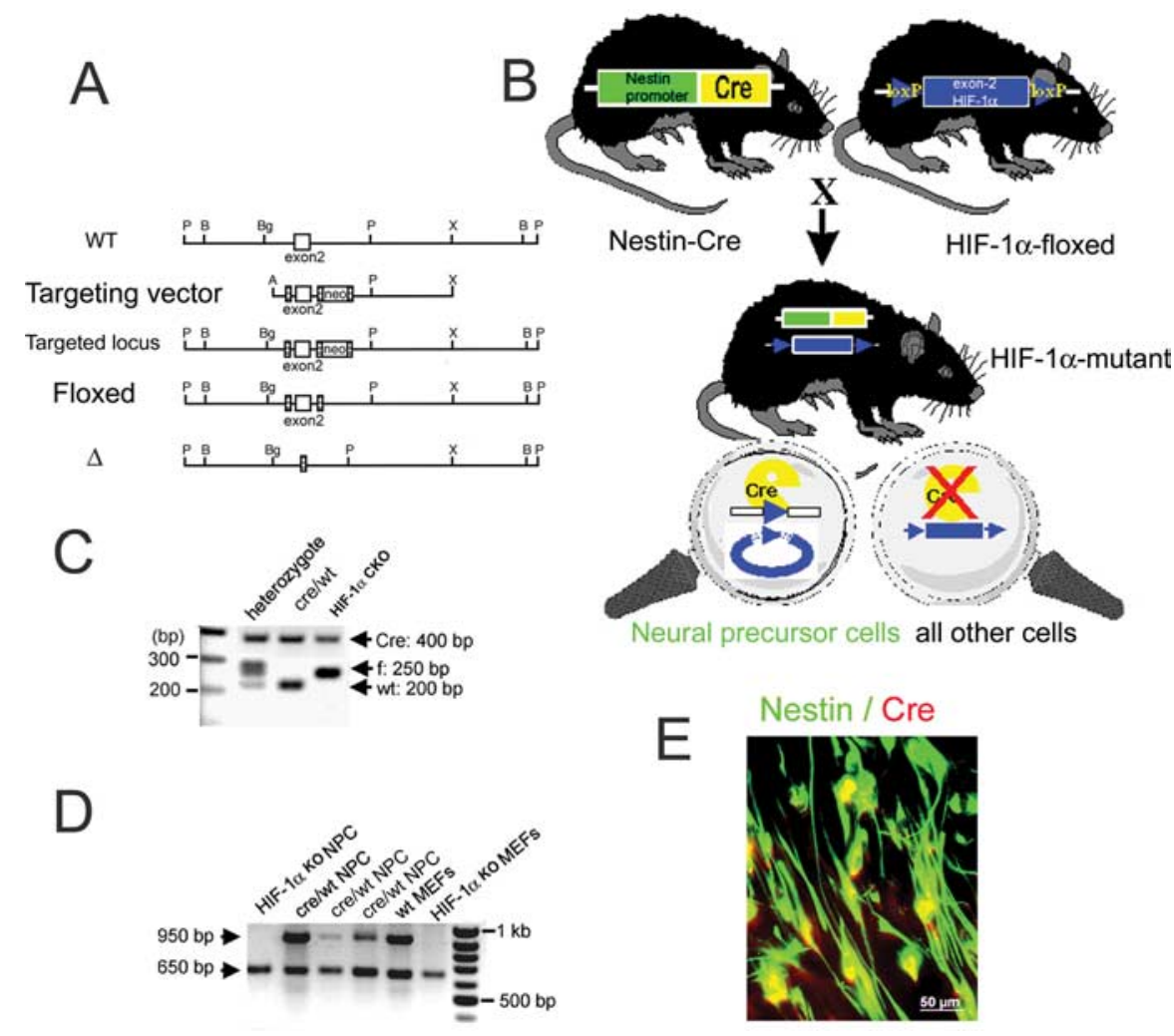

Figure 1. Generation and characterization of neural precursor cells deficient for HIF-1 $\alpha$. $\boldsymbol{A}$, Exon 2 of the Hif1a allele was flanked with loxP sites in two steps, resulting in generation of Hifla-floxed mice. Hatched quadrangles represent loxP sites. $\boldsymbol{B}$, Hifla-floxed mice were crossed with Nestin-Cre mice to generate HIF- $1 \alpha$ mutant mice (Nestin-Cre; Hif1 $a^{\text {IoxP/loxP }}$ or HIF-1 $1 \alpha$ CKO mice). C, PCR-based genotyping revealed embryos expressing both floxed Hifla allele (250 bp) and the Cre recombinase (400 bp), identifying double transgenic or HIF-1 $\alpha$ conditional mutants (HIF-1 $\alpha$ CKO), whereas wild-type Hif1a allele (200 bp) and (re expression identified control (cre/wt) embryos. NPCs dissected from brains of both types of embryos were kept in culture and subjected to additional analysis. NPCs from heterozygous embryos were discarded. D, PCR-based confirmation of Cre-mediated recombination in NPCs. Exon 2 of Hifla was excised by Cre-induced recombination in NPCs, resulting in appearance of a shorter 650 bp band. DNA derived from wt and HIF- $1 \alpha$ KO MEFs was used as a positive and a negative control. $\boldsymbol{E}$, Cre recombinase expression was restricted to NPCs in vitro (Nestin-positive), as revealed by double immunofluorescence for Cre and Nestin (yellow color indicates colocalization).

driven expression of Cre recombinase (Betz et al., 1996; Rajewsky et al., 1996). Exon 2 encodes the motif necessary for dimerization of HIF- $1 \alpha$ and HIF- $1 \beta$, binding of the HIF- 1 dimer to DNA, and its function as a transcription factor (Jiang et al., 1996). Our findings indicate that HIF- $1 \alpha$ promotes stem cell survival, growth, and dopaminergic differentiation, as well as survival of adult dopaminergic neurons.

\section{Materials and Methods}

Conditional inactivation of HIF-1 $\alpha$ in NPCs. A Cre/loxP system was used to generate HIF-1 $\alpha$-deficient NPCs (Le and Sauer, 2000; Nagy, 2000). Mice containing loxP-flanked Hifla exon 2 ( Hifla $a^{\text {loxP/loxP }}$ designated as Hifla-floxed mice) were kindly provided by R. S. Johnson (San Diego, CA). The strategy used to obtain loxP-flanked Hifla locus instead of the endogenous Hifla locus was described previously (Ryan et al., 2000) (Fig. 1A). Hifla-floxed targeted mice were crossed with mice expressing Cre recombinase under the control of the Nestin promoter, Nestin-Cre transgenic mice (JAXMICE; The Jackson Laboratory, Bar Harbor, ME). Nestin-Cre strain of mice was maintained in a C57BL/6 $\times \mathrm{SJL}$ and Hiflafloxed in a C57BL/ 6 background. Animals heterozygous for both Hiflafloxed and Nestin-Cre alleles were mated to Hifla-floxed homozygous animals to generate Nestin-Cre, Hifla $a^{\text {loxP/loxP }}\left(\mathrm{HIF}-1 \alpha^{\Delta}\right)$ mice. To distinguish HIF- $1 \alpha$ conditional knock-out (CKO) embryos/mice, a genomic PCR-based genotyping was applied using the following primers: floxed or wild-type (wt) HIF- $1 \alpha$ allele, $5^{\prime}$-GCA GTT AAG AGC ACT
AGT TG-3' and 5'-GGA GCT ATC TCT CTA GAC C-3', 250 bp product (floxed) or $200 \mathrm{bp}$ product (wild type); Cre recombinase primers, 5'-CCT GGA AAA TGC TTC TGT CCG-3' and 5'-CAG GGT GTT ATA AGC AAT CCC-3', 400 bp product (Fig. 1C). NPCs were dissected from frontal (fNPCs) or mesencephalic brain regions of HIF- $1 \alpha$ null embryos carrying the HIF- $1 \alpha$ conditional mutation (HIF- $1 \alpha$ CKO fNPCs and HIF- $1 \alpha$ CKO mNPCs, respectively) as described below. Removal of HIF- $1 \alpha$ exon 2 by Cre-induced recombination in NPCs was confirmed using the following primers: $5^{\prime}$-GCA GTT AAG AGC ACT AGT TG-3' and 5'-TGT TAA ATA AAA GCT TGG AC-3', amplifying a 650 bp fragment (Fig. $1 D$ ).

To exclude possible toxic effects of the Cre recombinase that could influence proliferation of NPCs, in all of our in vitro experiments, we compared HIF- $1 \alpha$ CKO NPCs with the cells containing the wt Hifla allele expressed in parallel with the Cre allele, referred to as cre/wt NPCs (Pfeifer et al., 2001).

Isolation, propagation, and differentiation of NPCs. Mesencephalic and frontal (cortical) NPCs were dissected from mice at E14. Pregnant females were killed according to National Institutes of Health guidelines and the approval of the local animal care committee. Tissue samples were incubated in $0.1 \mathrm{mg} / \mathrm{ml}$ papain (Roche, Mannheim, Germany)/DNase solution $\left(100 \mu \mathrm{g} / \mathrm{ml}\right.$; Roche) for $30 \mathrm{~min}$ at $37^{\circ} \mathrm{C}$, rinsed in PBS, incubated in antipain $(50 \mu \mathrm{g} / \mathrm{ml}$; Roche) for $30 \mathrm{~min}$ at $37^{\circ} \mathrm{C}$, and finally homogenized by gentle triturating using a firepolished Pasteur pipette. The cells were expanded as a monolayer culture by plating onto polyornithine-fibronectin precoated dishes in a density of 20,000 cells $/ \mathrm{cm}^{2}$ (Milosevic et al., 2005). The cells were maintained in serum-free DMEM (high glucose)/F-12 mixture (1:1) medium and supplemented with $20 \mathrm{ng} / \mathrm{ml}$ human recombinant epidermal growth factor and 20 $\mathrm{ng} / \mathrm{ml}$ basic fibroblast growth factor (both from PromoCell, Heidelberg, Germany). NPCs were expanded in 3\% oxygen (Storch et al., 2001; Milosevic et al., 2005).

Differentiation of NPCs was induced using defined media without mitogens but with 1\% FCS and $5 \mu \mathrm{m}$ forskolin (Sigma-Aldrich, Munich, Germany). Before electrophysiology, immunocytochemistry, or protein extraction, mNPCs were allowed to differentiate for 1 week. Electrophysiological analysis of mNPCs was also performed after a $20 \mathrm{~d}$ differentiation period.

In vitro VEGF administration. HIF- $1 \alpha \mathrm{CKO}$ and cre/wt mNPCs were treated in vitro with $50 \mathrm{ng} / \mathrm{ml}$ recombinant human VEGF (PAN Biotech, Aidenbach, Germany), applied once for $7 \mathrm{~d}$ of proliferation and once during consecutive $7 \mathrm{~d}$ differentiation period. Values obtained for treated cultures were normalized to untreated ones.

Clonogenic survival assay. Midbrain-derived or frontal NPCs were seeded in triplicate onto polyornithine-fibronectin precoated six-well plates $\left(1 \times 10^{3}\right.$ cells per well in $3 \mathrm{ml}$ of culture medium). Two weeks after incubation at $37^{\circ} \mathrm{C}$ in a reduced oxygen $(3 \%)$ atmosphere, the colonies were fixed in $70 \%$ ethanol and stained with $0.5 \%$ toluidine blue solution. The number of colonies obtained for cre/wt control NPCs was considered as $100 \%$, and colonies generated by HIF- $1 \alpha$ CKO NPCs were normalized to the control cells.

Immunoblotting. Mouse substantia nigra (SN) extracts or NPCs extracts were prepared as described previously (Milosevic et al., 2005). Proteins $(50-100 \mu \mathrm{g})$ were separated by $12 \%$ SDS-PAGE and transferred to nitrocellulose membranes. Antibodies used to probe blots were as 
follows: mouse monoclonal anti-proliferating cell nuclear antigen (PCNA) (Santa Cruz Biotechnology, Santa Cruz, CA); mouse monoclonal anti-Bcl-2 (Santa Cruz Biotechnology), mouse monoclonal anti-pro-caspase-3 (BD Transduction Laboratories, San Jose, CA); rabbit polyclonal anti-activated caspase-3 (CM1; BD PharMingen, San Diego, CA); mouse monoclonal anti-VEGF (Abcam, Cambridge, UK); chicken polyclonal anti-aldehyde dehydrogenase (ALDH1A1) (kindly provided by N. E. Sladek, Minneapolis, MN); mouse monoclonal anti-actin (MP Biomedicals, Eschwege, Germany); mouse monoclonal anti-glial fibrillary acidic protein (GFAP) (Chemicon, Hampshire, UK); rabbit polyclonal anti-HIF- $1 \alpha$ (Cayman Chemical, Ann Arbor, MI); rabbit polyclonal anti- $\beta$-tubulin III (anti-TUJ1; Covance, Richmond, CA); and horseradish peroxidase-conjugated secondary antibodies (Pierce, Rockford, IL).

Immunocytochemistry. NPCs were fixed with $4 \%$ paraformaldehyde in PBS for $10 \mathrm{~min}$ at room temperature, washed with $\mathrm{PBS}$, and counterstained with the DNA-binding dye $4^{\prime}$ 6-diamidino-2-phenylindole ( $2 \mu \mathrm{g} / \mathrm{ml}$ in PBS) for $15 \mathrm{~min}$ at room temperature, twice washed in PBS followed by incubation in blocking buffer $(10 \%$ FCS and $0.2 \%$ Triton X-100 in PBS, pH 7.2) for $30 \mathrm{~min}$ at room temperature. After incubation with the primary antibody (1 $\mathrm{h}$ at room temperature in blocking buffer), the cells were incubated with fluorescent secondary antibodies, Alexa Fluor 488 conjugate or Alexa Fluor 594 conjugate (Invitrogen, Carlsbad, CA). Coverslips were mounted onto glass slides and examined under a fluorescence microscope (Axiovert 200; Zeiss, Jena, Germany). Acquisition of the cells was performed using the imageanalysis software AxioVision 4 (Zeiss, Jena, Germany). The following primary antibodies were used for immunofluorescence: mouse monoclonal anti-nestin (BD Biosciences, San Jose, CA), mouse monoclonal anti-Cre recombinase (Chemicon), and rabbit polyclonal anti- $\beta$-tubulin III (anti-TUJ1; Covance).

Confocal microscopy. Activated caspase-3 localization in the SN was investigated by confocal laser scanning microscopy (LSM 510; Zeiss, Oberkochen, Germany) at an excitation wavelength of $594 \mathrm{~nm}$ (helium/ neon, red Alexa 594 immunofluorescence) and $488 \mathrm{~nm}$ (argon, yellowgreen Alexa 488 immunofluorescence).

Immunohistochemistry and stereological cell counts. After being fixed by cardiac perfusion ( $4 \%$ paraformaldehyde in phosphate buffer) both HIF- $1 \alpha \mathrm{KO}$ and cre/wt mice brains were postfixed for $2 \mathrm{~h}$ and dehydrated in $15 \%$ sucrose and $30 \%$ sucrose. Frozen brain samples were cut $(40 \mu \mathrm{m})$ in a cryostat; $10-20$ serial sections from SN levels were collected free floating in ice-cold PBS. Double immunostaining was performed with antisera for tyrosine hydroxylase (TH) (goat polyclonal anti-TH antibody, 1:100; Santa Cruz Biotechnology) and anti-activated caspase-3 (CM1, 1:2000; BD PharMingen), followed by incubation with fluorescent secondary antibodies (1:500, Alexa 488 or Alexa 594; Invitrogen). For stereology, groups of three to four transgenic mice of the same age (4 weeks old) were perfused as described above. TH-positive cells in the SN from HIF- $1 \alpha \mathrm{CKO}$ and cre/wt mice were selected for nonbiased quantitative stereology. Tissue sections, $40 \mu \mathrm{m}$ thick (8-12 slices), were chosen for analysis using systematic random sampling. The $\mathrm{SN}$ sections were immunostained with a rabbit antibody to TH (rabbit polyclonal; Santa Cruz Biotechnology) at a 1:500 dilution, biotinylated goat anti-rabbit secondary antibody, streptavidin-HRP (Vector Laboratories, Burlingame, CA), and DAB (Sigma-Aldrich). Before dehydration of floating slices, they were processed for Nissl ( $30 \mathrm{~s}$ in $0.5 \%$ toluidine blue in PBS) to facilitate counting. The intersection interval, counting frame size, and distance between counting frames were adjusted so that, whenever pos-

\begin{tabular}{ll} 
Primer sequence: forward: reverse & GenBank accession \# \\
\hline 5'-CAA CGG TCA CAG CAC TTC G-3' & NM_007438 \\
5'-GGC TCG ACC ATA GGA GAA AG-3' & \\
5'-CGA TTG AGG CTT CCT TCC C-3' & NM_139305 \\
5'-CTA ACT CTA TCT TTG GTC CCA CTT C-3' & \\
5'-GAA AAT GTC ACG ATG GGT TGT-3' & NM_007942 \\
5'-TGT TCT TCC ACC TCC ATT CTT T-3' & \\
5'-CTC ATT CTG GTC CTC ATC TCG-3' & NM_010149 \\
5'-CACCACAGA CAA CCA TCA CG-3' & \\
5'-AGG TTG TCT CCT GCG ACT TCA-3' & NM_001001303 \\
5'-GGT GGT CCA GGG TTT CTT ACT C-3' & \\
5'-GCC ATT GAA ACG GAT AAG GAA-3' & NM_010438 \\
5'-GGC TGA TCG GAA GGA GAC G-3' & \\
5'-TCG GGG AAA CCT CAA CACC-3' & NM_013551 \\
5'-CCT GGCCCA CAG CAT ACA T-3' & \\
5'-GCG GTT CCG TTA CCT GAT G-3' & NM_010699 \\
5'-GAA CCT CCT TCC ACT GCT CC-3' & \\
5'-GCT TCC TGC TCA TCA ATC GTA A-3' & NM_011400 \\
5'-CGA CCC TCT TCT TTC ATC TCC T-3' & \\
5'-TCA ACC GCT TTG GCA GAC-3' & NM_011401 \\
5'-CGA AGG GCA GTG GGA GAC-3' & \\
5'-GCT ACT GCC GTC CGA TTG-3' & NM_001025257 \\
5'-CTG CAG GGC TTC ATC GTT AC-3' & \\
5'-GAC ATT ACC TGG ATT CTG CTA CG-3' & NM_010228 \\
5'-AAG GAT GTC TTC CCC TGT GTA 5-3' & \\
5'-GGA CCT GGC AGC ACG AA-3' & NM_010612 \\
5'-CAC TTC AAA GGG AGT GGG G-3' & \\
5'-ACG CTG ATG ATA GTC CACCC-3' & NM_008029 \\
5'-CGC TGT CTG TCT GGT TAT CC-3' & \\
&
\end{tabular}

sible, a reasonable number of $\mathrm{TH}$-stained cells were sampled. The optical fractionator method was used to provide an unbiased estimation of the total number of dopaminergic neurons in the region of interest. Stereologic counting and estimates were done with the aid of Stereoinvestigator version 5.05.1 (MicroBrightField, Magdeburg, Germany) (Orb et al., 2004).

Electrophysiology. Patch-clamp analysis of mNPCs differentiated in vitro for 7 or $20 \mathrm{~d}$ was performed at room temperature using an inverted microscope DMIL (Leica, Bensheim, Germany) and an EPC-9 amplifier (HEKA Elektronik, Lambrecht, Germany). Recordings of voltage-gated ion channels were obtained in the whole-cell voltage-clamp mode by stepwise depolarizations with increasing amplitudes from the holding potential of -70 to $50 \mathrm{mV}$ in steps of $10 \mathrm{mV}$. Series resistance values were continuously measured during all recordings. The external bath solution contained the following (in mM): $142 \mathrm{NaCl}, 1 \mathrm{CaCl}_{2}, 8 \mathrm{KCl}, 6 \mathrm{MgCl}_{2}, 10$ glucose, and 10 HEPES, pH 7.4 (320 mOsm). Micropipettes were formed from thin-walled borosilicate glass (Science Products, Hofheim, Germany) with a Flaming Brown electrode puller P-97 (Sutter Instruments, Novato, USA) and a Micro Forge (Narishige, Tokyo, Japan). Electrodes had resistances of 2-4 M $\Omega$ when filled with the internal solution containing the following (in $\mathrm{mm}$ ): $153 \mathrm{KCl}, 1 \mathrm{MgCl}_{2}, 10 \mathrm{HEPES}, 5 \mathrm{EGTA}$, and 2 MgATP, pH 7.3 (305 mOsm). Whole-cell currents were low-pass filtered at $2-5 \mathrm{kHz}$, digitized at $10 \mathrm{kHz}$, and analyzed using PulseFit software (HEKA Elektronik) and Prism 4 (GraphPad Software, San Diego, CA). Data were expressed as mean \pm SEM. Statistical significance was considered at $p<0.05$ (Student's $t$ test, two-tailed, unpaired).

Determination of dopamine and metabolites. For determination of dopamine, norepinephrine, and their metabolites, striatal tissue was dissected and immediately frozen in liquid nitrogen. Five striata of each genotype were processed. Dopamine, norepinephrine, 3,4dihydroxyphenylacetic acid (DOPAC), and homovanillic acid were analyzed using standard HPLC techniques essentially as described previously (Gerlach et al., 1996).

Behavioral studies. Sensorimotor performance of HIF- $1 \alpha$ CKO compared with cre/wt mice was evaluated using the beam-walk paradigm. Mice were trained to pass a beam for 4 consecutive days. We used a 
A

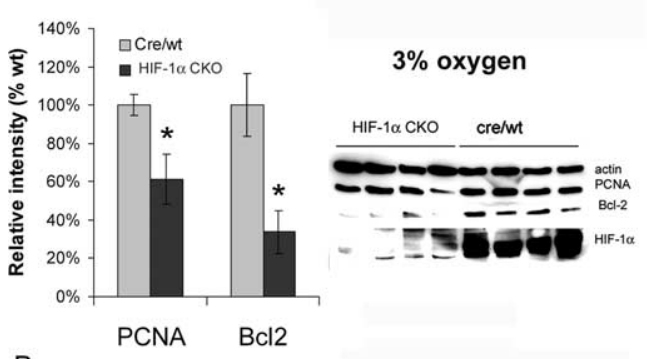

B

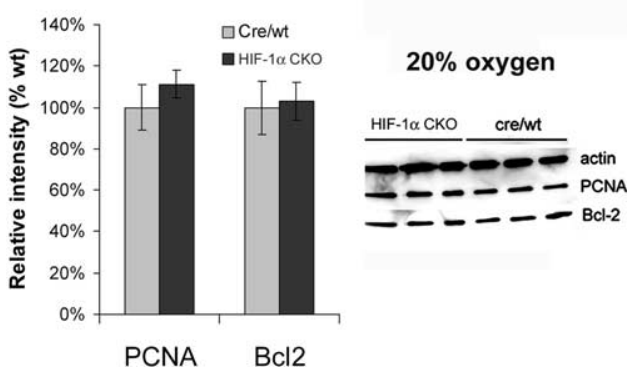

C

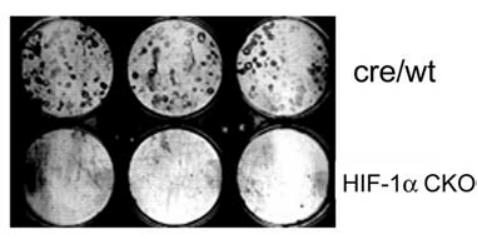

D

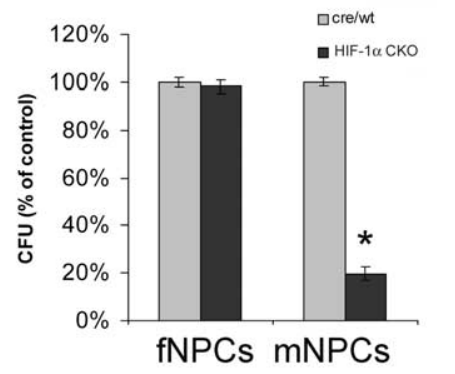

Figure 2. Survival and proliferation of HIF- $1 \alpha$ CKO mNPCs are impaired. $\boldsymbol{A}$, Western blot analysis of HIF-1 $\alpha$ wild-type and HIF-1 $\alpha$ CKO mNPCs grown in either 3 or $20 \%$ oxygen revealed impaired proliferation (PCNA) and survival (Bcl-2) of HIF- $1 \alpha$ CKO mNPCs. $\boldsymbol{B}$, Twenty percent of oxygen caused no changes in expression of PCNA and Bcl-2 in either cre/wt or HIF- $1 \alpha$ CKO mNPCs. C, Reduced number of clones formed by HIF-1 $\alpha$ CKO versus cre/wt mNPCs in $3 \%$ oxygen is shown. $\boldsymbol{D}$, Numbers of generated colonies [colony-forming units (CFU)], either fNPCs or mNPCs, expressed as a percentage of the colonies formed by cre/wt NPCs. ${ }^{*} p<0.05$ compared with cre/wt NPCs.

sected from both midbrain and frontal part of each embryonic brain and expanded in vitro. After genotyping, only NPCs containing the wt Hifla allele that were cre-positive (cre/wt), as well as NPCs containing the Hifl $\alpha$-floxed allele that were cre-positive (HIF-1 $\alpha \mathrm{CKO}$ ) were kept in culture for additional analysis (Fig. $1 C, D)$. HIF- $1 \alpha^{\Delta / \Delta}$ homozygous mutant myocyte enhancer factors (MEFs) and wt MEFs were used as a negative and positive control for the genotyping (Fig. 1D). Immunocytochemical staining confirmed expression of Cre recombinase in Nestinpositive NPCs (Fig. $1 E$ ).

Wild-type murine NPCs (cre/wt) and NPCs lacking exon 2 of the Hifla gene, designated as HIF- $1 \alpha$ CKO dissected from at least four different embryos were expanded in 3\% oxygen and checked for expression of HIF- $1 \alpha$ protein. In cre/wt NPCs, HIF- $1 \alpha$ protein was stabilized in $3 \%$ oxygen revealing a $120 \mathrm{kDa}$ band as seen by immunoblotting. This band was not present in HIF-1 $\alpha$ CKO cells (Fig. $2 A$ ). As soon as successful Cre-mediated excision was confirmed in NPCs, these cells were considered as HIF- $1 \alpha$ knock-outs. wooden beam with a length of $1 \mathrm{~m}$, a diameter of $4 \mathrm{~mm}$, and a rough surface to prevent slipping. Mice were motivated via the smell of the food within the target cage. On the fifth day, 10 trials per mouse were analyzed.

Spontaneous locomotion was measured for $30 \mathrm{~min}$ using an openfield setup. Transitions from one quadrant to another were scored. All open-field experiments were videotaped and analyzed subsequently by a blinded rater (J.L.).

$R N A$ extraction and quantitative real-time reverse transcription-PCR analysis. Total cellular RNA was extracted from NPCs using RNAeasy total RNA purification kit followed by treatment with RNase-free DNase (Qiagen, Hilden, Germany). Semiquantitative real-time one-step reverse transcription (RT)-PCR was performed using the Stratagene system (MX3000P; Stratagene, Heidelberg, Germany), and amplification was monitored and analyzed by measuring the binding of fluorescent SYBR Green I to double-stranded DNA. One microliter (50 ng) of total RNA was reverse transcribed and subsequently amplified using QuantiTect SYBR Green RT-PCR Master mix (Qiagen) and $0.5 \mu \mathrm{mol} / \mathrm{L}$ of both sense and antisense primers. The sequences for forward and reverse primers used for the target gene (TG) and the reference gene (RG) hydroxymethylbilane synthase are summarized in Table 1 . The relative RNA content was determined using the formula of the comparative cycle threshold $(\mathrm{Ct})$ : TG/RG = $2^{\mathrm{Ct}(\mathrm{RG})-\mathrm{Ct}(\mathrm{TG})}$ (Livak and Schmittgen, 2001). The efficiency of product formation by PCR was estimated from plots of Ct values versus serial dilutions, measured three times with different RNA samples.

Statistical analysis. Normally distributed data were subjected to statistical analyses as indicated (one- or two-way ANOVA) using the SigmaStat software package (Jandel, San Rafael, CA) and Prism 4. Results are expressed as the mean \pm SEM. Statistical significance was considered at $p<0.05$.

\section{Results}

Generation and characterization of HIF-1 $\alpha$ CKO mNPCs

Hifla-floxed targeted mice were crossed with mice expressing Cre recombinase under the control of the Nestin promoter (Nestin-Cre mice) to obtain Nestin-Cre; HIF-1 $\alpha^{\text {loxP/loxP }}\left(\mathrm{HIF}-1 \alpha^{\Delta}\right.$ ) mice referred to HIF- $1 \alpha$ CKO mice (Fig. $1 A, B$ ). NPCs were dis-

\section{proliferation of midbrain-derived NPCs}

$H I F-1 \alpha$ is important for survival and mNPCs generated from at least four different embryos were first expanded for 2 weeks in 3\% oxygen and then split for additional expansion for 2 weeks, in either 20 or $3 \%$ oxygen. Protein extracts were probed with the proliferation marker PCNA and prosurvival marker Bcl-2. Compared with cre/wt cells, expression of both proteins was significantly reduced in HIF- $1 \alpha$ inactive NPCs when they were expanded in 3\% oxygen. As shown in Figure $2 A$, PCNA expression was reduced to $61 \pm 13 \%(n=4 ; p=0.035$, one-way ANOVA), whereas Bcl-2 levels were only $34 \pm 11 \%$ in HIF- $1 \alpha$ CKO mNPCs $(n=4 ; p=0.015)$. When HIF- $1 \alpha$ was eliminated by $20 \%$ oxygen, PCNA and Bcl-2 expression did not significantly differ in HIF- $1 \alpha$ CKO mNPCs compared with cre/wt mNPCs (Fig. 2B).

Clonal assays confirmed the necessity of HIF- $1 \alpha$ for survival and proliferation of mNPCs. Mesencephalic NPCs derived from HIF- $1 \alpha$ CKO embryonic brains in 3\% oxygen produced $20 \pm 4 \%$ colonies normalized to $100 \%$ colonies formed by cre/wt NPCs (Fig. 2C,D).

\section{HIF-1 $\alpha$ is not necessary for survival and proliferation of frontal NPCs}

To test region-specific effects of HIF- $1 \alpha$ deletion in NPCs, we performed the same experimental procedure on frontal NPCs. Proliferation (PCNA protein expression) and survival (Bcl-2 protein expression) assessed by Western blotting did not reveal any significant differences in HIF- $1 \alpha$ null compared with cre/wt NPCs in either 3 or $20 \%$ oxygen (Fig. $3 A, B$ ). Frontal NPCs derived from HIF- $1 \alpha \mathrm{CKO}$ embryonic brains in 3\% oxygen produced a similar number of colonies compared with cre/wt samples $(98 \pm 3 \%)$ (Fig. 2D). 
A

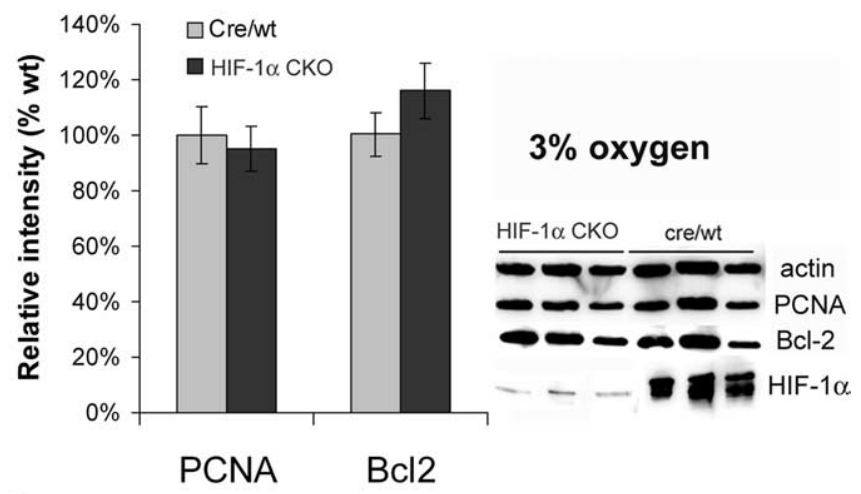

B

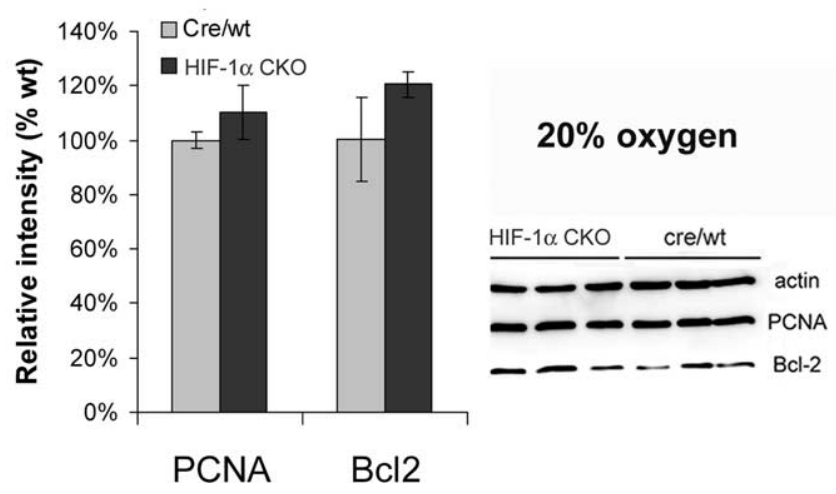

Figure 3. Survival and proliferation of HIF- $1 \alpha$ CKO fNPCS. $\boldsymbol{A}, \boldsymbol{B}$, Western blot analysis of HIF- $1 \alpha$ wild-type and HIF- $1 \alpha$ CKO fNPCs grown in either 3 or $20 \%$ oxygen showed no changes in expression of proliferation marker PCNA and the prosurvival marker BCl-2.

HIF-1 $\alpha$ is important for in vitro neuronal and dopaminergic differentiation of midbrain-derived NPCs

Whole-cell extracts for Western blotting were acquired from NPCs after 4 weeks of proliferation and after 1 week of differentiation. Extracts were separated and probed with the neuronal marker (TUJ1), the glial marker (GFAP), or TH, a marker for dopaminergic neurons. As shown in Figure $4 A$, neuronal and glial markers were not significantly changed in fNPCs, whereas differentiated HIF- $1 \alpha$ CKO mNPCs exhibited a significant reduction in TH expression, $35 \pm 4 \%$ of wt $(p<0.001)$. Neuronal differentiation and morphology of NPCs from frontal cortex was not affected by HIF- $1 \alpha$ deletion as confirmed by immunocytochemical analysis of frontal NPCs (Fig. 4B). In both KO and $\mathrm{cre} / \mathrm{wt}$ differentiated ANPCs, extensive neuronal processes were observed. Furthermore, protein expression of TUJ1 and GFAP did not vary between two different cell types (Fig. 4C). However, TUJ1 staining on cultured mNPCs 1 week after differentiation in $3 \%$ oxygen showed an altered morphology in HIF- $1 \alpha$ CKO $\mathrm{mNPC}$ compared with cre/wt NPCs. Cre/wt neurons were more mature, exhibiting longer neurites (Fig. 4D).

Electrophysiological analyses of voltage-gated ion channels showed significantly decreased maximal sodium inward currents of HIF- $1 \alpha$ CKO mNPCs $(116.9 \pm 33.9 \mathrm{pA}) 7 \mathrm{~d}$ after in vitro differentiation compared with cre/wt NPCs $(318.2 \pm 77.7 \mathrm{pA}$; $n=12$ for each genotype; $p=0.032, t$ test), whereas no significant reduction was calculated for potassium outward rectifying currents (Fig. 5). After $20 \mathrm{~d}$ of mNPC differentiation, values for sodium and potassium currents were increased in both HIF- $1 \alpha$ $\mathrm{CKO}$ and cre/wt cells without altering the difference between the

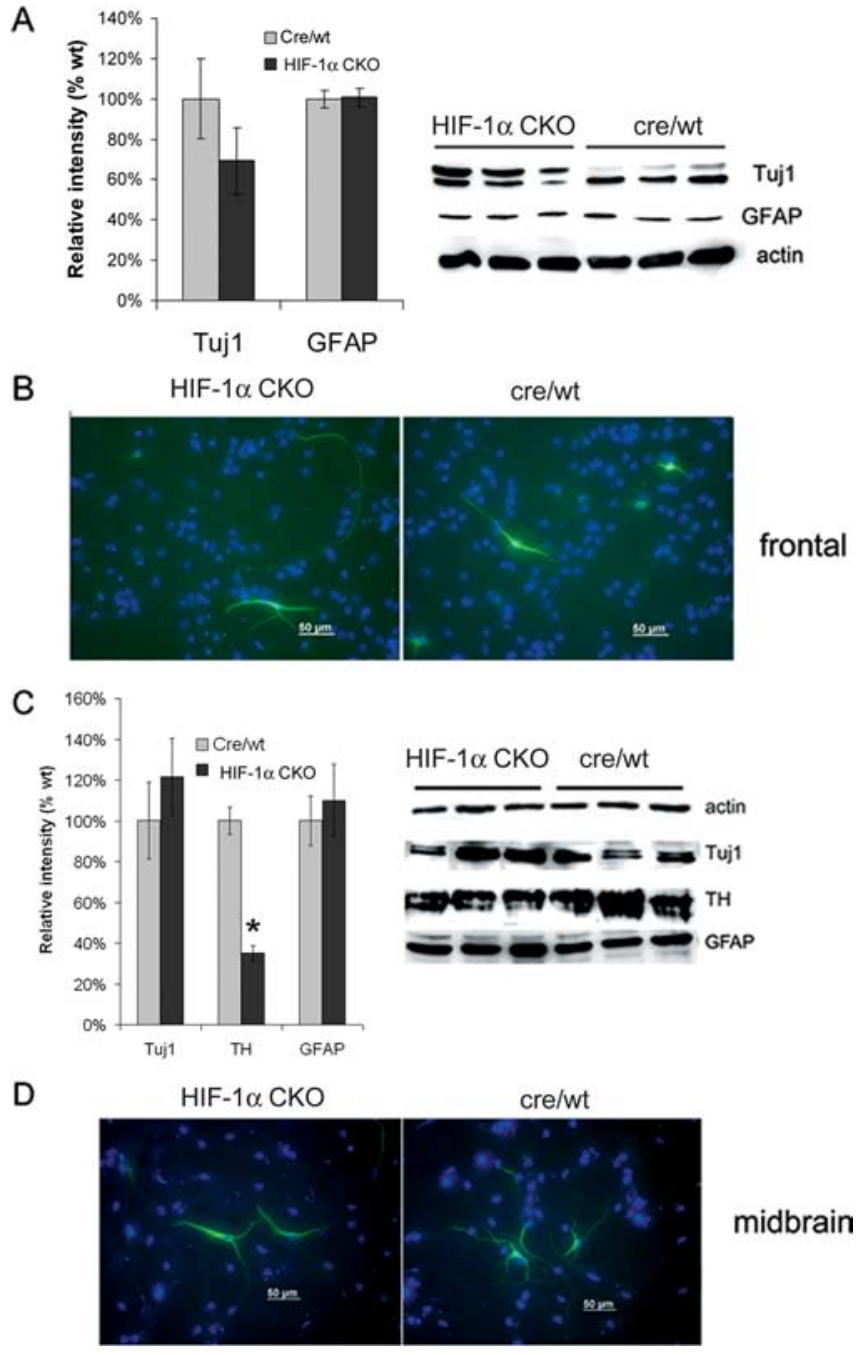

Figure 4. Differentiation potential of frontal (cortical) and mesencephalic NPCs. A-D, Frontal $(\boldsymbol{A}, \boldsymbol{B})$ and mesencephalic $(\boldsymbol{C}, \boldsymbol{D})$ NPCs were first expanded in 3\% oxygen for at least eight passages and then were subjected to differentiation for 1 week, which was also in reduced oxygen. Protein extracts were probed with the early neuronal marker $\beta$-tubulin III (TUJ1), glial marker (GFAP), marker for dopaminergic neurons (TH), and loading control ( $\beta$-actin). Data in $\boldsymbol{A}$ and $C$ are mean \pm SEM values from at least three independent experiments. ${ }^{*} p<0.05$ when compared with cre/wt NPCs. Immunofluorescence TUJ1 staining of differentiated HIF- $1 \alpha$ CKO and cre/wt frontal $(\boldsymbol{B})$ or mesencephalic $(\boldsymbol{D})$ NPCs is shown. Immunostaining of midbrainderived NPCs has revealed diverse neuronal morphology characterized like reduced axonal branching in CKO versus wt cells.

two genotypes (data not shown). In contrast, there was no significant difference in maximal amplitudes of sodium and potassium currents between HIF- $1 \alpha \mathrm{CKO}$ and cre/wt frontal NPCs $7 \mathrm{~d}$ after in vitro differentiation (data not shown).

HIF- $1 \alpha$ supports the development and/or survival of dopaminergic neurons

SN was dissected from 4 -week-old HIF- $1 \alpha$ CKO mice and their cre/wt littermates. At the time of analysis, these animals were macroscopically identical. Tissue extracts were analyzed via immunoblotting. Neuronal $\beta$-tubulin III (TUJ1) expression did not significantly differ between genotypes, whereas TH protein was reduced to $59 \pm 5 \%$ in HIF- $1 \alpha$ CKO mice $(n=5 ; p=0.008, t$ test). The expression of ALDH1A1, another early marker of SN dopaminergic neurons, was reduced to $39 \pm 19 \%(n=5$; $p=$ 0.002). Prosurvival protein $\mathrm{Bcl}-2$ was reduced to $43 \pm 12 \%(n=$ 
A
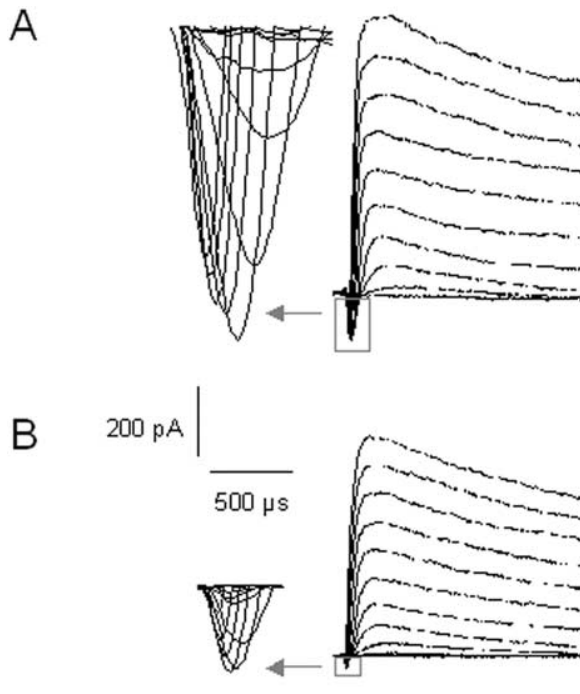

$1 \mathrm{nA}$

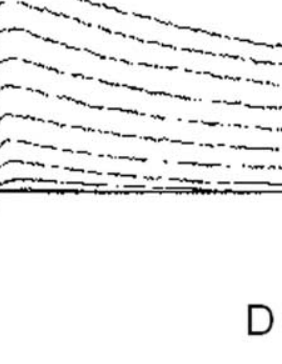

C

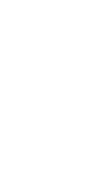

$\mathrm{mV}$
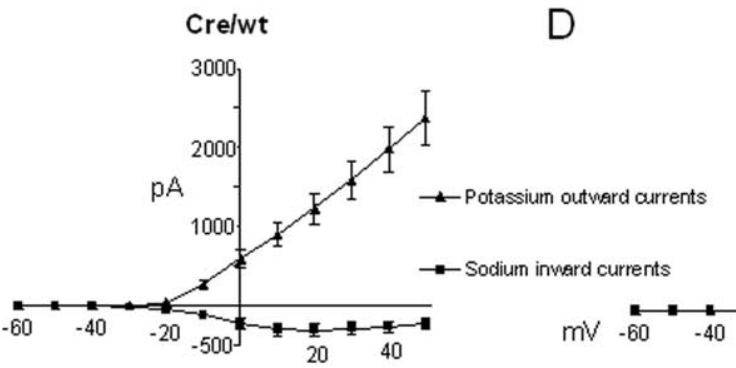

HIF-1 $\alpha-C K O$

E

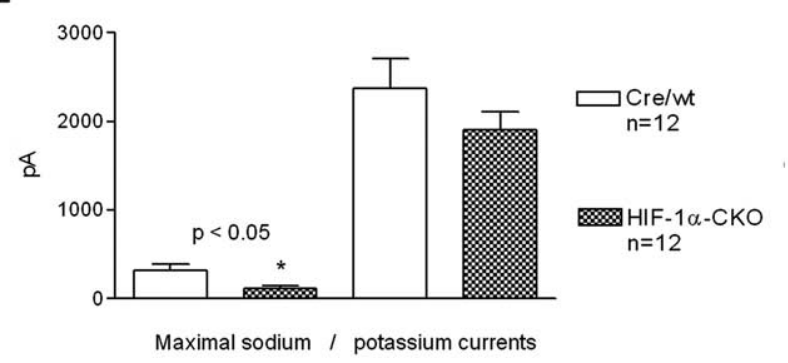

Figure 5. Voltage-gated ion channels of murine mesencephalic NPCs after $7 \mathrm{~d}$ in vitro differentiation. $A, B$, Recordings of cre/wt $(\boldsymbol{A})$ and HIF-1 $\alpha$ CKO $(\boldsymbol{B})$ cells were obtained in whole-cell voltage-clamp mode by stepwise depolarizations with increasing amplitudes from the holding potential of -70 to $50 \mathrm{mV}$ in steps of $10 \mathrm{mV}$. Note the inlays showing sodium inward currents that were more pronounced in cre/wt $(\boldsymbol{A})$ than in HIF- $1 \alpha$ CKO (B) cells. $\boldsymbol{C}, \boldsymbol{D}$, Current-voltage plots of $\mathrm{mNPC}$ s show higher values for mean amplitudes of sodium inward and potassium outward currents in cre/wt (C) than in HIF- $1 \alpha$ CKO (D) cells. Maximal sodium inward currents $(\boldsymbol{E})$ of HIF- $1 \alpha$ CKO NPCs were significantly decreased compared with cre/wt cells ( $p=0.032, t$ test), whereas no significant reduction was calculated for potassium outward rectifying currents; all current values are shown as means \pm SEM. in the SN of HIF- $1 \alpha$ CKO mice $(n=4)$ showed a robust and significant reduction compared with cre/wt SN (total number of TH-positive neurons in the SN, $7489 \pm$ 477 vs $10,817 \pm 903$, respectively, or $69 \pm$ $6 \%$ of cre/wt) (Fig. 6C). However, the number of TH-positive cells in another brain region, ventral tegmental area (VTA), remained unaffected $(n=4)$ (Fig. $6 C)$. Nissl staining of both cre/wt and HIF- $1 \alpha$ CKO brain slices revealed no difference in the $\mathrm{SN}(50,096 \pm 246$ vs $48,913 \pm 2006$, respectively; $n=3$ ), dentate gyrus $(375,897 \pm 61,210$ vs $364,628 \pm$ $30,580)$, and medial habenula $(84,560 \pm$ 6141 vs $79,318 \pm 5740$ ). In addition, biochemical measurements of dopamine, norepinephrine, and their metabolites (DOPAC and HVA) did not reveal any significant differences between genotypes (data not shown). These findings are well in line with other mouse models of Parkinson's disease, in which moderate losses of dopaminergic neurons within SN are readily compensated (Orb et al., 2004).

An evaluation of potential sensorimotor deficits using analysis of beam walking and spontaneous locomotion failed to show any difference between genotypes (data not shown). Open-field behavior of HIF- $1 \alpha \mathrm{CKO}$ and cre/wt mice was quantified for $30 \mathrm{~min}$. Statistical analysis by twotailed $t$ test revealed no statistical differences between HIF- $1 \alpha$ CKO and cre/wt mice ( $n=7$ of both genotypes).

\section{Expression analysis of HIF- $1 \alpha$ - regulated genes revealed VEGF and VEGF receptors as major downstream genes of HIF- $1 \alpha$ in mNPCs}

The expression of VEGF and VEGF receptor (VEGFR) subtypes as HIF- $1 \alpha$ regulated genes was explored and quantified in expanded mNPCs and ANPCs by real-time RT-PCR. VEGF expression was reduced in HIF- $1 \alpha$ CKO mNPCs compared with both cre/wt mNPCs and fNPCs $(n=7 ; p=$ 0.036) (Table 2, Fig. 7A) but showed no change between both fNPC subtypes. Expression levels of VEGFR-1 (Flt-1) were significantly higher in mNPCs compared $5 ; p=0.03)$. Pro-caspase- 3 was cleaved in HIF- $1 \alpha$ CKO mice SN extracts, resulting in reduced levels of $20 \pm 15 \%(n=5$; $p=$ 0.008 ), but activated caspase- 3 was increased because it was not detectable in extracts from cre/wt mice. VEGF protein was reduced in SN taken from HIF- $1 \alpha$ CKO compared with cre/wt mice (Fig. 6A). Double-immunofluorescence labeling of brain slices in combination with confocal laser scanning microscopy indicated that the activated, cleaved form of the caspase- 3 was predominantly present in dopaminergic (TH-positive) cells in the $\mathrm{SN}$ of HIF- $1 \alpha$ CKO mice (Fig. $6 B$ ). In the SN of cre/wt mice, we could not find any cells positive for both caspase- 3 and $\mathrm{TH}$.

Finally, stereological non-biased counts of TH-positive cells with fNPCs independent of HIF-1 $\alpha$ expression (Table 2). VEGFR-2 (Flk-1) expression was 2.7- to 3.8-fold increased in HIF- $1 \alpha$ CKO compared with cre/wt NPCs in both mesencephalic and frontal NPCs and 31- to 44-fold higher in mNPCs compared with $\mathrm{fNPCs}$ independent of HIF- $1 \alpha$ expression $(n=4 ; p=0.018)$ (Table 2, Fig. 7A). VEGFR-3 (Flt-4) expression did not differ between HIF- $1 \alpha$ CKO and cre/wt mNPCs. We did not detect differences in mRNA levels of the EPO receptor (EPOR) in HIF- $1 \alpha$ CKO and cre/wt mNPCs and fNPCs (data not shown). Additionally, there were no detectable mRNA levels of EPO in all four cell types. Significantly lower expression of neuronal glucose transporter 3 (Slc2a3) in both ANPC subtypes and in HIF-1 $\alpha$ 
CKO mNPCs compared with cre/wt $\mathrm{mN}$ PCs were seen (Table 2). In contrast, we did not detect significant differences in mRNA levels of various other nonneuronal HIF- $1 \alpha$-regulated genes with respect to the four NPC subtypes (Table 2).

\section{VEGF stimulates proliferation and dopaminergic differentiation of HIF- $1 \alpha$ CKO mNPCs in vitro}

Because VEGF seemed to be reduced in HIF- $1 \alpha \mathrm{CKO} \mathrm{mNPCs}$ and potentially mediate the effects of HIF- $1 \alpha$ in these cells, we tried to rescue HIF- $1 \alpha \mathrm{CKO}$ mNPCs by supplementing culture media with VEGF. Proliferation, analyzed by PCNA expression, was significantly increased in HIF- $1 \alpha$ CKO mNPCs after application of VEGF $(50 \mathrm{ng} / \mathrm{ml})(47 \pm 5 \%$ in untreated vs $75 \pm$ $4 \%$ in VEGF-treated cells; $p<0.05$, twoway ANOVA). In addition, $\mathrm{TH}$ protein was elevated from $26 \pm 5 \%$ of control in untreated HIF- $1 \alpha$ CKO mNPCs to $68 \pm$ $6 \%$ after VEGF treatment $(n=4 ; p<0.05)$ (Fig. $7 B, C$ ). Proliferation of cre/wt cells did not significantly change after VEGF treatment. The prosurvival protein Bcl-2 and the neuronal marker TUJ1 were not altered by VEGF treatment in either cell type (Fig. $7 B, C$ ). Thus, only partial recovery of HIF- $1 \alpha$ CKO mNPCs proliferation and differentiation was induced by VEGF in vitro administration.

\section{Discussion}

Here we demonstrate for the first time that HIF- $1 \alpha$ is important for proliferation, survival, and differentiation of murine tissue-specific midbrain-derived NPCs. Thus, HIF- $1 \alpha$ may be an essential mediator with respect to the beneficial effects of lowered oxygen tension on NPCs (Studer et al., 2000; Storch et al., 2001; Milosevic et al., 2005). Adult HIF-1 $\alpha$-deficient mice also showed deficits of SN dopaminergic neurons, indicating that HIF- $1 \alpha$ is not only important for proliferation and differ-

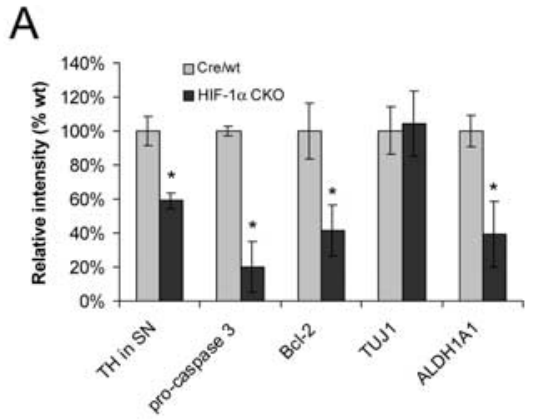

B

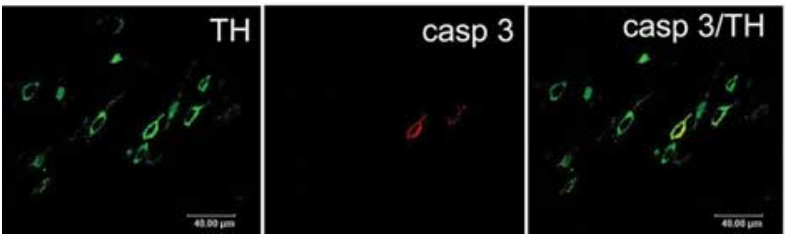

C

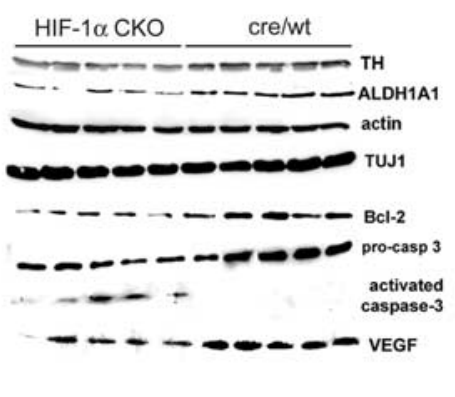

Figure 6. Degeneration of the SN of HIF- $1 \alpha$ CKO mice. $A$, Immunoblots demonstrating TH and ALDH1A1 protein expression, neuronal $\beta$-tubulin III (TUJ1) expression, apoptotic effectors such as BCl-2, pro-caspase-3, and activated caspase-3, and HIF- $1 \alpha$ downstream target genes such as VEGF, all parallel assessed in the SN of HIF- $1 \alpha$ CKO and cre/wt mice. $B$, SN of HIF- $1 \alpha$ CKO mice viewed by confocal microscopy showing colocalization of activated caspase-3 (CM1; red) in TH-immunoreactive cells (green). $\boldsymbol{C}$, Stereological investigation revealing the number of dopaminergic (TH-positive) neurons in the SN and the ventral tegmental area of HIF- $1 \alpha$ CKO in relation to cre/wt mice is presented. Scale bar, $40 \mu \mathrm{m}$. Data are expressed as mean \pm SEM values from five independent experiments. ${ }^{*} p<0.05$ when compared with cre/wt NPCs.

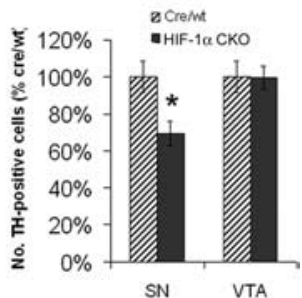

entiation of mNPCs in vitro but may also mediate regeneration or survival in vivo.

Gas phase oxygen concentrations of $1-5 \%$ correspond to the physiological environment in embryonic tissue and adult brain (Silver and Erecinska, 1998). These "physiological" concentrations seem to be required for stem cell maintenance (Gustafsson et al., 2005; Covello et al., 2006). Recently, we demonstrated that "room air" damages murine midbrain-derived NPCs, initiating a variety of cellular events (Milosevic et al., 2005). However, it was not clear whether 3\% oxygen affects NPC proliferation and differentiation via an HIF-1-dependent signaling pathway or via another mechanism.

Table 2. Gene expression profile of HIF-1 $\alpha$-regulated genes in NPCs grown under 3\% oxygen condition ${ }^{a}$

\begin{tabular}{|c|c|c|c|c|c|}
\hline Genes (protein) & HIF-1 $\alpha$ CKO mNPCs & cre/wt mNPCs & HIF-1 $\alpha$ CK0 1NPCs & cre/wt fNPCs & $p$ value $^{b}$ \\
\hline Aldoa (aldolase A) & $5.66 \pm 0.66$ & $6.94 \pm 2.02$ & $6.88 \pm 1.31$ & $9.45 \pm 0.76$ & 0.16 \\
\hline Car9 (carboanhydrase 9) & $0.01 \pm 0.00$ & $0.02 \pm 0.01$ & $0.06 \pm 0.02$ & $0.14 \pm 0.09$ & 0.10 \\
\hline Epo (erythropoietin) & n.d. & n.d. & n.d. & n.d. & \\
\hline EpoR (erythropoietin receptor) & $0.07 \pm 0.01$ & $0.06 \pm 0.01$ & $0.06 \pm 0.02$ & $0.09 \pm 0.02$ & 0.69 \\
\hline Gapdh (glycerin-aldehyde-3-phosphatase) & $93.1 \pm 24.7$ & $166.2 \pm 34.6$ & $173.1 \pm 43.0$ & $278.6 \pm 21.9$ & 0.24 \\
\hline Hk1 (hexokinase 1) & $2.71 \pm 0.23$ & $1.96 \pm 0.35$ & $1.71 \pm 0.24$ & $2.56 \pm 0.20$ & 0.23 \\
\hline Ldha (lactat deydrogenase A) & $26.0 \pm 2.54$ & $74.4 \pm 21.3$ & $31.3 \pm 2.29$ & $57.6 \pm 6.79$ & 0.18 \\
\hline Slc2a1 (glucose transporter 1) & $0.65 \pm 0.05$ & $1.24 \pm 0.61$ & $0.92 \pm 0.43$ & $1.92 \pm 0.88$ & 0.38 \\
\hline SIc2a3 (glucose transporter 3) & $0.16 \pm 0.01^{*}$ & $0.38 \pm 0.06$ & $0.07 \pm 0.02^{*++}$ & $0.17 \pm 0.04^{++}$ & 0.00015 \\
\hline Vegf (vascular endothelial growth factor) & $8.85 \pm 2.42^{*}$ & $18.7 \pm 8.9$ & $13.7 \pm 1.4^{+}$ & $18.4 \pm 6.1$ & 0.036 \\
\hline VEGFR1/FIt1 (VEGF receptor 1/FMS-like tyrosine kinase 1) & $0.21 \pm 0.11$ & $0.19 \pm 0.07$ & $0.04 \pm 0.03^{+}$ & $0.07 \pm 0.02^{+}$ & 0.028 \\
\hline VEGFR2/FIk1 (VEGF receptor 2/fetal liver kinase 1) & $0.30 \pm 0.06^{*}$ & $0.11 \pm 0.06$ & $0.0095 \pm 0.001^{* *,++}$ & $0.0025 \pm 0.001^{++}$ & 0.0008 \\
\hline VEGFR3/Flt4 (VEGF receptor 3/FMD-like tyrosine kinase 4) & $0.07 \pm 0.03$ & $0.11 \pm 0.09$ & $0.0029 \pm 0.001$ & $0.0039 \pm 0.001$ & 0.19 \\
\hline
\end{tabular}

n.d., Not detectable.

${ }^{a}$ mRNA levels of the target gene relative to the housekeeping gene $\mathrm{Hmbs}$ (mean $\pm \mathrm{SEM}$ ) from three to seven experiments.

${ }^{b} p$ values from ANOVA tests for multiple group comparisons ( $\left.n=3-7\right)$; post hoc $t$ test revealed statistical significant differences with ${ }^{*} p<0.05$ and ${ }^{* *} p<0.01$ when compared with control NPCs (cre/wt mNPCs or cre/wt fNPCs); ${ }^{+} p<$ 0.05 and ${ }^{++} p<0.01$ when compared with the respective mNPC subtype. 
A
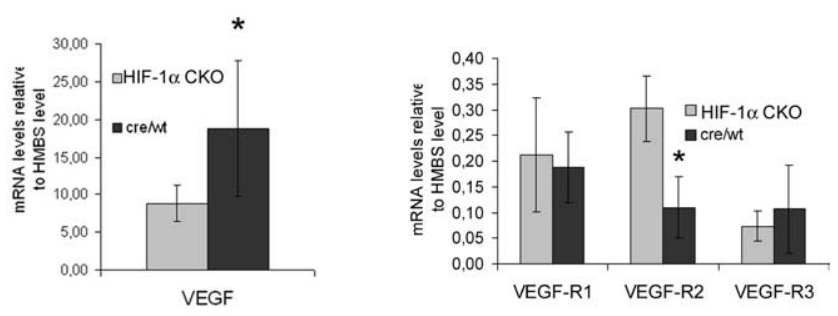

\section{B}
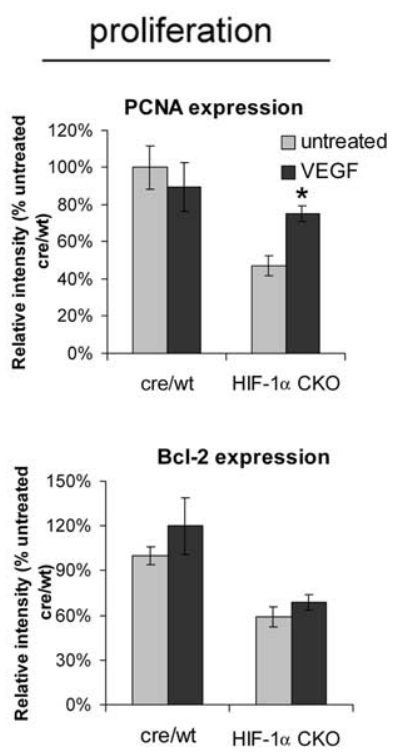
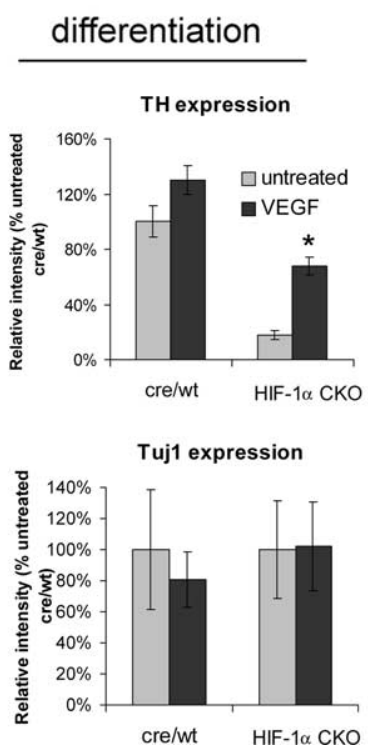

Figure 7. VEGF partially restores proliferation and dopaminergic differentiation of HIF-1 $\alpha$ CKO mesencephalic NPCs expanded in 3\% oxygen. $\boldsymbol{A}$, Compared with cre/wt, VEGF mRNA expression is reduced in HIF- $1 \alpha$ CKO mNPCs, whereas VEGFR-2 expression is increased in the CKO as observed by semiquantitative RT-PCR analysis. $\boldsymbol{B}$, $\boldsymbol{C}$, Proliferation ( $\boldsymbol{B}$ ) (PCNA and BCl-2 protein expression) and differentiation (C) (TH protein expression, TUJ1 expression) markers observed in HIF-1 $\alpha$ CKO mNPC untreated and treated with VEGF relative to cre/wt untreated values are shown. VEGF ( $50 \mathrm{ng} / \mathrm{ml}$ ) was applied for $7 \mathrm{~d}$ of proliferation followed by $7 \mathrm{~d}$ of differentiation. Data are mean \pm SEM values from at least four independent experiments. ${ }^{*} p<0.05$ when compared with cre/wt mNPCs.

In an attempt to elucidate the role of HIF- $1 \alpha$ in $3 \%$ oxygenstimulated survival, proliferation, and differentiation in murine NPCs, we conditionally targeted HIF- $1 \alpha$ in NPCs using a Cre/ loxP-based system (Ryan et al., 2000). Tomita et al. (2003) created mice with neural-cell-specific HIF-1 $\alpha$ deficiency, exhibiting hydrocephalus, neuronal loss, and impairment of spatial memory. In the present paper, we focused on the midbrain dopaminergic system, investigating possible alterations of dopaminergic markers (ALDH1A1, TH, dopamine, and metabolites) and expression of major HIF- $1 \alpha$ downstream proteins, such as VEGF and EPO. Deletion of HIF- $1 \alpha$ in $\mathrm{mN}$ PCs had an impact on neuronal morphology in vitro accompanied by a significant reduction of sodium inward currents elicited by depolarizations, suggesting an altered morphological and functional differentiation compared with cre/wt mNPCs. In this regard, cortical NPCs remained unaffected. Midbrain-derived NPCs also showed decreased levels of TH after differentiation. In contrary to the major finding by To-

mita et al. (2003), which was apoptosis in the cortical plate resulting in cortical atrophy in HIF- $1 \alpha$ null mutant mice, we did not observe any significant changes regarding proliferation, survival, and neuronal differentiation in frontal (cortical) NPCs. In addition, we did not notice any alterations in cortical brain regions in 4 -week-old mice, which, according to Tomita et al. (2003), at that age should have been visible. Our HIF-1 $\alpha$ CKO mice were macroscopically indistinguishable from cre/wt mice but exhibited morphological alterations in the SN. However, our mice did not show major locomotor deficits or dopamine deficiency within striatal tissue, suggesting that the moderate loss of dopaminergic neurons at that age was well compensated. HIF- $1 \alpha$ functional mutants developed by Tomita et al. (2003) were created also using Cre/loxP technology but excising exons $13-15$ of the HIF- $1 \alpha$ gene while we excised exon 2 . HIF- $1 \alpha$ mutant protein in the report by Tomita et al. (2003) lacked the transactivation domain, whereas our HIF- $1 \alpha$ mutant mice lack the DNA binding domain. Thus, the HIF- $1 \alpha$ mutant protein was either absent or functionally inert (Jiang et al., 1996; Ema et al., 1999). At this point, it is not clear whether the differences seen between two HIF- $1 \alpha \mathrm{CKO}$ mice originate as a consequence of a different genetic manipulation, differences in genetic background, or other reasons.

HIF- $1 \alpha$ might be protective in some neurological disorders (Soucek et al., 2003). Neuroprotective effects of EPO on dopaminergic neurons suggested a possible positive effect of hypoxia via HIF- $1 \alpha$ and subsequent EPOR expression (Demers et al., 2005). In line with recent studies suggesting a pivotal role of HIF- $2 \alpha$ in regulating EPO expression (Chavez et al., 2006), we did not find relevant EPO expression in our cell system and no differences of EPOR expression in HIF- $1 \alpha \mathrm{CKO}$ versus cre/wt mNPCs, suggesting that EPOR signaling is not involved in HIF- $1 \alpha$-dependent survival, proliferation, and differentiation of mNPCs. Conversely, VEGF as another downstream target gene of HIF- $1 \alpha$ acts as a direct neurotrophic or even neuroprotective factor (Matsuzaki et al., 2001; Sun et al., 2003). We detected a notable reduction in VEGF mRNA expression in HIF- $1 \alpha$ CKO compared with cre/wt mNPCs and a most likely compensatory upregulation of VEGFR-2. SN of HIF- $1 \alpha$ CKO mice expressed less VEGF protein compared with cre/wt. We further demonstrated that proliferation and dopaminergic differentiation of HIF- $1 \alpha \mathrm{CKO}$ $\mathrm{mNPCs}$ were partially recovered after in vitro administration of VEGF, indicating that other target genes besides VEGF are involved. The lack of HIF-1 $\alpha$ coincided with apoptotic cell death in dopamine-producing, TH-positive cells in the SN of adult mice. Procaspase- 3 was cleaved in the SN of HIF- $1 \alpha$ CKO mice confirmed by in situ caspase- 3 activation. Expression of the anti-apoptotic protein Bcl- 2 in SN of HIF- $1 \alpha \mathrm{CKO}$ mice was decreased, likely as a consequence of an effector caspase activation (Milosevic et al., 2003). However, HIF-1 $\alpha$ CKO mice exhibited absence of gross locomotor and sensorimotor behavioral deficits, which is in line with other mouse models with moderate dopaminergic deficits (Masliah et al., 2000; Orb et al., 2004).

HIF- $1 \alpha$ activates the expression of hypoxia-inducible genes that contain a hypoxia response element located in the promoter or enhancer regions. Hypoxia induces TH mRNA expression in rat mesencephalic cultures (Leclere et al., 2004), whereas HIF- $1 \alpha$ contributes to induction of TH transcription in PC12 cells (Schnell et al., 2003). Our findings indicate that HIF- $1 \alpha$ represents an important factor for in vitro neuronal and dopaminergic differentiation, as well. Conditional knock- 
out of HIF- $1 \alpha$ affected SN neurons in young adult mice. In addition to the decline of $\mathrm{TH}$ expression, we observed a reduction in another neuronal marker enriched in $\mathrm{SN}$, ALDH1A1. ALDH1A1 is shown to be expressed in A9 dopaminergic neuronal group, the most vulnerable site in PD (Chung et al., 2005). We showed a prominent reduction in the number of dopaminergic (TH-positive) neurons in the SN of HIF- $1 \alpha$-deficient mice. Many animal models with degeneration of dopaminergic neurons show specificity for dopaminergic neurons in SN compared with VTA (Liss et al., 2005; Maingay et al., 2006). Accordingly, HIF- $1 \alpha$-deficient mice have no deficit in A10 dopaminergic neurons. Moreover, as revealed by Nissl staining, other neuronal types (e.g., GABAergic neurons in gyrus dentatus or $\mathrm{SN}$, catecholaminergic neurons in medial habenula) likely also remained unaffected in HIF- $1 \alpha$ $\mathrm{CKO}$, because examined brain regions did not exhibit difference in neuronal cell numbers when compared with cre/wt mice.

Our data represent first evidence for a role of HIF- $1 \alpha$ for dopaminergic development and survival. We also identified an important downstream gene: VEGF. However, because VEGF supplementation only partly antagonizes the lack of HIF- $1 \alpha$, future studies need to identify other downstream targets of HIF- $1 \alpha$ that mediate this effect and may therefore represent potential drug targets for regeneration or protection of $\mathrm{SN}$ dopaminergic neurons, the cell type selectively affected in Parkinson's disease.

\section{References}

Alvarez-Buylla A, Lim DA (2004) For the long run: maintaining germinal niches in the adult brain. Neuron 41:683-686.

Betz UA, Vosshenrich CA, Rajewsky K, Muller W (1996) Bypass of lethality with mosaic mice generated by Cre-loxP-mediated recombination. Curr Biol 6:1307-1316.

Chavez JC, Baranova O, Lin J, Pichiule P (2006) The transcriptional activator hypoxia inducible factor 2 (HIF-2/EPAS-1) regulates the oxygendependent expression of erythropoietin in cortical astrocytes. J Neurosci 26:9471-9481.

Chung S, Hedlund E, Hwang M, Kim DW, Shin BS, Hwang DY, Jung Kang U, Isacson O, Kim KS (2005) The homeodomain transcription factor Pitx3 facilitates differentiation of mouse embryonic stem cells into AHD2-expressing dopaminergic neurons. Mol Cell Neurosci 28:241-252.

Covello KL, Kehler J, Yu H, Gordan JD, Arsham AM, Hu CJ, Labosky PA, Simon MC, Keith B (2006) HIF-2 $\alpha$ regulates Oct-4: effects of hypoxia on stem cell function, embryonic development, and tumor growth. Genes Dev 20:557-570.

Demers EJ, McPherson RJ, Juul SE (2005) Erythropoietin protects dopaminergic neurons and improves neurobehavioral outcomes in juvenile rats after neonatal hypoxia-ischemia. Pediatr Res 58:297-301.

Ema M, Hirota K, Mimura J, Abe H, Yodoi J, Sogawa K, Poellinger L, Fujii-Kuriyama Y (1999) Molecular mechanisms of transcription activation by HLF and HIF $1 \alpha$ in response to hypoxia: their stabilization and redox signal-induced interaction with $\mathrm{CBP} / \mathrm{p} 300$. EMBO J 18:1905-1914.

Ferriero DM (2005) Protecting neurons. Epilepsia 46:45-51.

Gage FH (2003) Brain, repair yourself. Sci Am 289:46-53.

Gerlach M, Gsell W, Kornhuber J, Jellinger K, Krieger V, Pantucek F, Vock $\mathrm{R}$, Riederer P (1996) A post mortem study on neurochemical markers of dopaminergic, GABA-ergic and glutamatergic neurons in basal ganglia-thalamocortical circuits in Parkinson syndrome. Brain Res 741:142-152.

Greenberg DA, Jin K (2005) From angiogenesis to neuropathology. Nature 438:954-959.

Gustafsson MV, Zheng X, Pereira T, Gradin K, Jin S, Lundkvist J, Ruas JL, Poellinger L, Lendahl U, Bondesson M (2005) Hypoxia requires notch signaling to maintain the undifferentiated cell state. Dev Cell 9:617-628.
Ivanovic Z, Dello Sbarba P, Trimoreau F, Faucher JL, Praloran V (2000) Primitive human HPCs are better maintained and expanded in vitro at 1 percent oxygen than at 20 percent. Transfusion 40:1482-1488.

Iyer NV, Kotch LE, Agani F, Leung SW, Laughner E, Wenger RH, Gassmann M, Gearhart JD, Lawler AM, Yu AY, Semenza GL (1998) Cellular and developmental control of $\mathrm{O}_{2}$ homeostasis by hypoxia-inducible factor 1 $\alpha$. Genes Dev 12:149-162.

Jiang BH, Rue E, Wang GL, Roe R, Semenza GL (1996) Dimerization, DNA binding, and transactivation properties of hypoxia-inducible factor 1 . J Biol Chem 271:17771-17778.

Junk AK, Mammis A, Savitz SI, Singh M, Roth S, Malhotra S, Rosenbaum PS, Cerami A, Brines M, Rosenbaum DM (2002) Erythropoietin administration protects retinal neurons from acute ischemia-reperfusion injury. Proc Natl Acad Sci USA 99:10659-10664.

Le Y, Sauer B (2000) Conditional gene knockout using cre recombinase. Methods Mol Biol 136:477-485.

Leclere N, Andreeva N, Fuchs J, Kietzmann T, Gross J (2004) Hypoxiainduced long-term increase of dopamine and tyrosine hydroxylase mRNA levels. Prague Med Rep 105:291-300.

Liss B, Haeckel O, Wildmann J, Miki T, Seino S, Roeper J (2005) K-ATP channels promote the differential degeneration of dopaminergic midbrain neurons 8:1742-1751.

Livak KJ, Schmittgen TD (2001) Analysis of relative gene expression data using real-time quantitative PCR and the 2(-Delta Delta C(T)) Method. Methods 25:402-408.

Maingay M, Romero-Ramos M, Carta M, Kirik D (2006) Ventral tegmental area dopamine neurons are resistant to human mutant alpha-synuclein overexpression. Neurobiol Dis 23:522-532.

Masliah E, Rockenstein E, Veinbergs I, Mallory M, Hashimoto M, Takeda A, Sagara Y, Sisk A, Mucke L (2000) Dopaminergic loss and inclusion body formation in alpha-synuclein mice: implications for neurodegenerative disorders. Science 287:1265-1269.

Matsuzaki H, Tamatani M, Yamaguchi A, Namikawa K, Kiyama H, Vitek MP, Mitsuda N, Tohyama M (2001) Vascular endothelial growth factor rescues hippocampal neurons from glutamate-induced toxicity: signal transduction cascades. FASEB J 15:1218-1220.

Milosevic J, Hoffarth S, Huber C, Schuler M (2003) The DNA damageinduced decrease of Bcl-2 is secondary to the activation of apoptotic effector caspases. Oncogene 22:6852-6856.

Milosevic J, Schwarz SC, Krohn K, Poppe M, Storch A, Schwarz J (2005) Low atmospheric oxygen avoids maturation, senescence and cell death of murine mesencephalic neural precursors. J Neurochem 92:718-729

Morrison SJ, Csete M, Groves AK, Melega W, Wold B, Anderson DJ (2000) Culture in reduced levels of oxygen promotes clonogenic sympathoadrenal differentiation by isolated neural crest stem cells. J Neurosci 20:7370-7376.

Nagy A (2000) Cre recombinase: the universal reagent for genome tailoring. Genesis 26:99-109.

Orb S, Wieacker J, Labarca C, Fonck C, Lester HA, Schwarz J (2004) Knockin mice with Leu9'Ser $\alpha 4$-nicotinic receptors: substantia nigra dopaminergic neurons are hypersensitive to agonist and lost postnatally. Physiol Genomics 18:299-307.

Pfeifer A, Brandon EP, Kootstra N, Gage FH, Verma IM (2001) Delivery of the Cre recombinase by a self-deleting lentiviral vector: efficient gene targeting in vivo. Proc Natl Acad Sci USA 98:11450-11455.

Rajewsky K, Gu H, Kuhn R, Betz UA, Muller W, Roes J, Schwenk F (1996) Conditional gene targeting. J Clin Invest 98:600-603.

Ryan HE, Lo J, Johnson RS (1998) HIF- $1 \alpha$ is required for solid tumor formation and embryonic vascularization. EMBO J 17:3005-3015.

Ryan HE, Poloni M, McNulty W, Elson D, Gassmann M, Arbeit JM, Johnson RS (2000) Hypoxia-inducible factor- $1 \alpha$ is a positive factor in solid tumor growth. Cancer Res 60:4010-4015.

Sakanaka M, Wen TC, Matsuda S, Masuda S, Morishita E, Nagao M, Sasaki R (1998) In vivo evidence that erythropoietin protects neurons from ischemic damage. Proc Natl Acad Sci USA 95:4635-4640.

Schnell PO, Ignacak ML, Bauer AL, Striet JB, Paulding WR, Czyzyk-Krzeska MF (2003) Regulation of tyrosine hydroxylase promoter activity by the von Hippel-Lindau tumor suppressor protein and hypoxia-inducible transcription factors. J Neurochem 85:483-491.

Semenza GL (1999) Regulation of mammalian $\mathrm{O}_{2}$ homeostasis by hypoxiainducible factor 1. Annu Rev Cell Dev Biol 15:551-578. 
Sharpless NE, DePinho RA (2004) Telomeres, stem cells, senescence, and cancer. J Clin Invest 113:160-168.

Silver I, Erecinska M (1998) Oxygen and ion concentrations in normoxic and hypoxic brain cells. Adv Exp Med Biol 454:7-16.

Soucek T, Cumming R, Dargusch R, Maher P, Schubert D (2003) The regulation of glucose metabolism by HIF-1 mediates a neuroprotective response to amyloid beta peptide. Neuron 39:43-56.

Storch A, Paul G, Csete M, Boehm BO, Carvey PM, Kupsch A, Schwarz J (2001) Long-term proliferation and dopaminergic differentiation of human mesencephalic neural precursor cells. Exp Neurol 170:317-325.

Studer L, Csete M, Lee SH, Kabbani N, Walikonis J, Wold B, McKay R (2000) Enhanced proliferation, survival, and dopaminergic differentiation of CNS precursors in lowered oxygen. J Neurosci 20:7377-7383.
Sun Y, Jin K, Xie L, Childs J, Mao XO, Logvinova A, Greenberg DA (2003) VEGF-induced neuroprotection, neurogenesis, and angiogenesis after focal cerebral ischemia. J Clin Invest 111:1843-1851.

Tomita S, Ueno M, Sakamoto M, Kitahama Y, Ueki M, Maekawa N, Sakamoto H, Gassmann M, Kageyama R, Ueda N, Gonzalez FJ, Takahama Y (2003) Defective brain development in mice lacking the Hif- $1 \alpha$ gene in neural cells. Mol Cell Biol 23:6739-6749.

Wenger RH (2002) Cellular adaptation to hypoxia: $\mathrm{O}_{2}$-sensing protein hydroxylases, hypoxia-inducible transcription factors, and $\mathrm{O}_{2}$-regulated gene expression. FASEB J 16:1151-1162.

Yasuhara T, Shingo T, Muraoka K, Kameda M, Agari T, Wen Ji Y, Hayase H, Hamada H, Borlongan CV, Date I (2005) Neurorescue effects of VEGF on a rat model of Parkinson's disease. Brain Res 1053:10-18. 